\title{
Grandes Figuras de la Ginecobstetricia Colombiana
}

\author{
JOSE DEL CARMEN ACOSTA
}

Por Fernando Sánchez Torres*

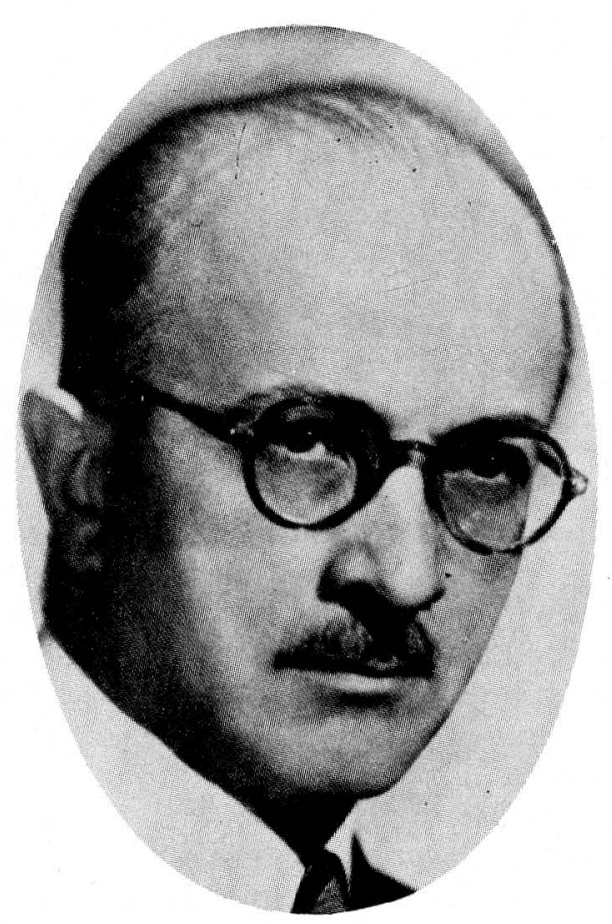

José del Carmen Acosta Villaveces, hijo de Concepción Villaveces y del ingeniero José del Carmen Acosta, nació en Soacha (Cundinamarca) el 16 de febrero de 1894, en la hacienda "El Vínculo". Bachiller en filosofía y letras del Colegio de San Bartolomé, en 1910. Cursó medicina en la Universidad Nacional, doctorándose el 14 de julio de 1917 con la tesis "Contribución al estudio de la hematología en Bogotá".

\footnotetext{
* Profesor Titular, Emérito y Honorario, de la Universidad Nacional. Miembro Fundador de la Sociedad Colombiana de Historia de la Medicina.
} 
Gracias a su inteligẹncia y a su consagración al estudio y al trabajo el doctor Acosta Villaveces logró pronto un rápido ascenso profesional: jefe de Clínica Interna (1917), jefe de Clínica Quirúrgica (1918), secretario de la Facultad de Medicina de la Universidad Nacional (1921-1930), miembro de número de la Academia Nacional de Medicina (1921), profesor de Clínica Obstétrica (1931), decano de la Facultad de Medicina de la Universidad Nacional (1934-35), decano de la Facultad de Medicina de la Universidad Javeriana (1942), fundador y presidente en dos ocasiones de la Sociedad Colombiana de Obstetricia (1943-1962), director del Instituto Materno Infantil (1944-1953), presidente de la Primera Convención Nacional de Obstetricia y Ginecología (1953), presidente de la Academia Nacional de Medicina (1952-54), director del Hospital San Juan de Dios (1953-1966), presidente de la Confederación Médica Panamericana (1954), presidente de la Federación Médica Colombiana (1954). Entre sus trabajos científicos publicados figuran los siguientes: "Algunas observaciones sobre escarlatina en Bogotá", "Evolución del sistema nervioso", "Notas sobre el tratamiento de la sífilis del sistema nervioso central", "Los extractos hipofisiarios en la práctica obstétrica", "Notas sobre varicocele pelviano", "Ventajas de la operación cesárea segmentaria", "Pelvis viciada por claudicación", "Tratamiento de la infección puerperal generalizada con antivirus en inyección intravenosa”, "Indicaciones de las operaciones cesáreas corporal y segmentaria", "Un caso de inversión uterina", "Tratamiento para la toxemia empleado en el Instituto Materno Infantil", "Tratamiento paliativo de los cánceres inoperables del útero con uretano intraarterial", "El aborto terapéutico". En 1936 fundó el Boletín Anual de Clínica Obstétrica del Hospital San Juan de Dios, donde fueron publicados algunos de los trabajos científicos elaborados en el servicio a su cargo. Este Boletín, infortunadamente, tuvo una efímera existencia. El doctor Acosta, además, estimuló y dirigió personalmente muchísimos estudios para tesis de grado de los que eran sus discípulos, a los cuales -como dijera Alberto Cárdenas - "prestó siempre la más generosa, la más inagotable asistencia, sin que las premuras de su vida fueran jamás obstáculo para esta voluntaria labor de conducción intelectual". En efecto, José del Carmen Acosta poseyó en alto grado la virtud del discipulismo, entendiendo ésta como una fuerza de atracción derivada de múltiples cualidades, particularmente de la capacidad de dar con generosidad.

En sus clases de Clínica Obstétrica su discurso no era cautivante. Demasiado pausado en la exposición, de voz asordinada y parco en los conceptos, daba a veces la impresión de que se esforzara por seleccionar los términos para ser exacto y preciso en la lección. Su modestia lo inhibía para hacer alarde de su cultura médica. No era de aquellos profesores de relumbrón que arrancan palmas al auditorio, pero cuyas enseñanzas se apagan a la par con el aplauso. En el quirófano era prudente, elegante y recursivo; las dificultades las sorteaba con facilidad, gracias a su disposición y buen juicio quirúrgico. Verlo ejercer la tocología era fascinante; su habilidad para intervenir era asombrosa. En sus manos todo parecía fácil: la versión, la mutación, el fórceps . . . La operación cesárea, de la que era pionero entre nosotros, la prodigaba con sentido restrictivo, cuando estaba plenamente indicada.

Donde verdaderamente se veía grande, donde adquiría los perfiles del maestro, era fuera de la cátedra. Su actuar en cualquier campo estuvo despojado de mezquinas pasiones, y su decidir, que llevó siempre el sello de la equidad, fueron para todos una extraordinaria y hermosa lección. Cuando a él se acudía en procura de un concepto médico o de un consejo personal, se sentía la certidumbre de que la duda y la inquietud iban a ser satisfechas por el más capaz de los médicos y por el más capaz de los hombres.

Próximo a cumplir medio siglo de entrega al ejercicio de su profesión, el doctor Acosta estaba colocado en el sumo pedestal que la categoría de valores le señaló. Poseedor de todos los títulos que nuestros círculos médicos y docentes otorgan a sus miembros distinguidos, el Estado mismo había reconocido su invaluable contribución al bie- 
nestar público, premiándolo con la Gran Cruz de Boyacá. Con ocasión del Cuarto Congreso Latinoamericano de Obstetricia y Ginecología, reunido en Bogotá en julio de 1962, los más eminentes especialistas del Continente le rindieron un emocionado homenaje. Rodeado del respeto de la sociedad y de todos sus colegas y discípulos, el profesor Acosta falleció en Bogotá, en marzo de 1966.

Haciendo un balance objetivo de lo que representó José del Carmen Acosta en la historia de la ginecobstetricia colombiana puede aceptarse que durante cerca de cuarenta años fue el epicentro de la actividad obstétrica nacional. Al lado suyo se formaron los mejores especialistas de la época. Por eso se consideraba que era él la cabeza visible y acatada de una verdadera escuela obstétrica. En efecto, el Instituto Materno Infantil de Bogotá bajo su sabia dirección llegó a ser, durante muchos años, la sede de esa escuela.

La producción escrita del doctor Acosta fue relativamente reducida. Algunas de sus publicaciones tuvieron en su momento señalada importancia. Infortunadamente, todo lo que tenía para transmitir no quedó registrado en libro alguno. Sus alumnos lo recogieron y usufructuaron, es cierto, pues sus lecciones eran sabias, producto de su amplia cultura y de su prolongada experiencia. De ahí que pueda afirmarse que su magna obra fueron las incontables promociones de médicos que ayudó a formar, como también los muchos especialistas que estructuró sólidamente.

Corresponde al profesor José del Carmen Açosta la prioridad en Colombia de haber ejecutado la cesárea segmentaria, que relegó a la corporal. Dejemos que sea él mismo quien nos refiera este hecho:

“En el año de 1920, el día 1o. de julio, siendo jefe de Clínica en el Servicio del profesor Rueda Acosta, practiqué, acompañado por el interno de servicio, hoy doctor Luis F. Buenaventura, la primera cesárea segmentaria efectuada en Bogotá, en una mujer de pelvis estrecha y con una gran infección amniótica; en ella se empleó la técnica de Schikelé, de Estrasburgo; en el mismo año se repitió en un caso análogo, pero ambos tuvieron una terminación fatal para la madre; sin embargo, en el año siguiente se practicó de nuevo, en otro caso de infección amniótica, con resultado completamente satisfactorio".

Habiendo revisado los libros de estadística de aquella época que reposan en el Instituto Materno Infantil, elaborados por el profesor Acosta con sin igual diligencia y preciosismo, encontramos que esa primera cesárea segmentaria se hizo a la paciente Carolina Hernández de Rodríguez y que el niño pesó 3.800 gramos.

La primera cesárea vaginal de que tengamos noticia se ejecutó también en el servicio que dirigía el profesor Miguel Rueda Acosta, en 1921. No obstante que indagamos por los detalles de dicha operación, particularmente por el nombre del cirujano y la fecha, no nos fue posible encontrarlos. Nos asiste la sospecha de que el autor pudo ser el doctor Acosta, jefe de clínica. De no ser así, el cirujano fue el doctor Rueda y el ayudante el doctor Acosta, como ocurrió con la práctica de la primera cesárea extraperitoneal, llevada a cabo en Bogotá el 28 de junio de 1927 en el Hospital San Juan de Dios, siguiendo la técnica de Döderlein, es decir, por vía paravesical.

A partir de 1931 se sistematizó la cesárea segmentaria transperitoneal sin aislamiento en aquellos casos llamados "puros". Por iniciativa del doctor Acosta se abandonó, en 1936, la incisión del segmento a cambio de la disociación digital transversa, que -según él- "es un procedimiento más anatómico y mucho menos cruento que la incisión”. La primera cesárea siguiendo esta técnica se hizo en la maternidad de San Juan de Dios el día 8 de enero de 1936, con éxito materno-fetal. 
Entre sus trabajos científicos vale la pena reseñar el relacionado con el empleo del antivirus por vía intravenosa como tratamiento de la fiebre puerperal. Recordemos que en la década de los años veinte la infección puerperal continuaba siendo un azote de las maternidades. Muchas sustancias se habían ensayado con miras a suprimir, o por lo menos a reducir, tan peligrosa complicación. Así tenemos: el oxiformol en vapores, las duchas vaginales con permanganato de potasio o con lisoformo, o con solución de Dakin (cloruro de cal, carbonato de soda y bicarbonato de soda). La trementina en inyecciones también se utilizaba, al igual que los coloides de plata, el mercurio y los arsenicales. La antivirus-terapia (antivirus de Bersredka) tenía buena aceptación en las infecciones puerperales localizadas. Basándose en este hecho el profesor Acosta Villaveces, en asocio del eminente bacteriólogo Federico Lleras Acosta, ensayó la antivirusterapia intravenosa en los casos de infección generalizada. En 1932 publicó una comunicación preliminar sobre sus resultados.

De esta experiencia llama la atención el rigor científico seguido por los autores. En consideración a que los antivirus se preparaban con medios de cultivo fuertemente peptonados y que al aplicarlos por vía intravenosa podían ocasionar fenómenos graves de tipo anafiláctico, el doctor Acosta y sus colaboradores emprendieron el estudio experimental inyectando los antivirus a conejos y recogiendo cuidadosamente las reacciones que presentaban los animales, previamente infectados con estreptococo hemolítico. De la fase experimental pasaron luego a la de aplicación clínica en mujeres con septicemia puerperal comprobada con hemocultivos. Analizando los resultados, por cierto muy escasos, el doctor Acosta anotaba: "No obstante el número reducido de observaciones, estas nos permiten fundar una gran presunción de que hemos logrado encontrar un tratamiento efectivo para la septicemia puerperal estreptocóccica, contra la cual hasta hoy estábamos prácticamente desarmados".

Una más amplia experiencia demostró que con el antivirus intravenoso no estaba resuelto el problema. Sin embargo, al analizar la metodología seguida debe abonarse la seriedad de la investigación, particularmente -como ya anotamos- el rigor científico seguido.

En 1956, con ocasión del 69 aniversario de la fundación de la Academia de Medicina de Medellín, el doctor Acosta disertó sobre un tema muy controvertido en ese momento, como era el llamado "aborto terapéutico". Durante el Congreso Internacional de Obstetricia realizado en Roma 1902, el famoso tocólogo francés Pinard abogó por que se le diera paso al aborto terapéutico, señalando una amplia gama de indicaciones, particularmente la tuberculosis pulmonar activa, las cardiopatías y las nefropatías de cualquier tipo. Viniendo de semejante autoridad, las recomendaciones de Pinard tuvieron amplia acogida en todo el mundo. Por supuesto que en Colombia nunca ocurrió así, por ser nuestro Código Penal absolutamente restrictivo. No obstante el doctor Acosta se lamentaba de que se preconizara la vigencia amplia de la interrupción del embarazo por indicaciones médicas. "Increíble - decía- que un hombre tan capacitado y tan buen clínico como el profesor Pinard hubiera avocado la resolución de estos problemas en forma tan parcializada y tan unilateral". En su disertación Acosta Villaveces, en términos técnicos, científicos, demuestra que al aborto terapéutico, además de ser inconveniente moralmente, es científicamente inútil para salvar la vida de la madre. En su concepto, ninguna indicación médica tenía cabida para justificar su práctica. "El aborto terapéutico -son sus palabras- es un endriago que devora vidas inocentes".

El profesor Acosta Villaveces, además de todo, fue un magnífico administrador y director hospitalario. Su paso por la dirección del Instituto Materno Infantil y por el Hospital San Juan de Dios, en Bogotá, dejó honda huella. En el primero, como ya dijimos, adelantó sin igual labor asistencial y académica, desde su fundación en 1944 hasta 1953, cuando pasó a dirigir el segundo. 
A solicitud del doctor Acosta, la Junta General de la Beneficencia de Cundinamarca emitió el Acuerdo número 6 del 3 de febrero de 1948, creando la Escuela de Auxiliares de Enfermeras Parteras, adscrita al Instituto Materno Infantil. Dicha entidad fue aprobada por el Ministerio de Higiene el 1o. de marzo de 1948 e inició labores el 1o. de junio del mismo año. Como en el Hospital San Juan de Dios funcionaba una Escuela de Auxiliares de Enfermería, la Junta General de Beneficencia, por Acuerdo Número 41 de 1950, fundió las dos escuelas en una sola, estableciendo en su artículo 2o. que "la duración de estudios sería de dos años, el primero en los Servicios de Enfermería del Hospital de San Juan de Dios y el segundo en los Servicios de Maternidad'.. Desde entonces la mencionada escuela ha venido proporcionándole al país un personal de alta capacitación técnica.

Al Instituto Materno Infantil le dedicó el profesor Acosta lo mejor de su entusiasmo y la mayor parte de su tiempo. Sentía tanto afecto por la institución que, teniendo en cuenta la ausencia de recursos económicos para dotarla de los equipos necesarios, de su propio peculio contribuyó a subsanar algunas de esas faltas. Por ejemplo, donó al hospital la dotación para el laboratorio clínico y para el departamento de radiología. Apenas justo, entonces, que la Junta General de la Beneficencia de Cundinamarca, atendiendo la solicitud del personal científico del Instituto, acordara en 1953 dar a esta maternidad el nombre de "Concepción Villaveces de Acosta", en homenaje a la señora madre del personaje del cual nos hemos ocupado.

\section{BIBLIOGRAFIA}

ACOSTA, J. del C. "Contribución al estudio de la hematología en Bogotá”. Tesis de grado. Universidad Nacional. Bogotá, 1917. "Ventajas de la operación cesárea segmentaria". Rev. Méd. de Colombia 1: 129, 1930.

"Pelvis viciada por claudicación". Rev. Méd. de Colombia 2: 433, 1932.

Y LLERAS, F. "Tratamiento de la infección puerperal generalizada con antivirus en inyección intravenosa". Rev. de la Fac. de Med. Bogotá, 1: 357, 1932.

“Notas sobre el varicocele pelviano”. Rev. Méd. de Bogotá, 44: 1162, 1934.

"Indicaciones de las operaciones cesáreas corporal y segmentaria". Boletín Anual de Clínica Obstétrica. Ed. Centro, Bogotá. 1936.

"Tratamientos para la toxemia empleados en el Instituto Materno Infantil de Bogotá”. Rev. Colombiana Obst. y Gin. 5: 99, 1954.
— "Un caso de inversión uterina". Rev. Hosp. San Juan de Dios. Bogotá, 2: 235, 1954.

Y FONNEGRA, A. "Tratamiento paliativo de los cánceres inoperables del útero con uretano intra-arterial". Rev. Hosp. San Juan de Dios, Bogotá, 3: 221, 1955.

“El aborto terapéutico". Antioquia Médica. Medellín. 6: $428,1956$.

CARDENAS, A. "Discurso en homenaje al Académico José del C. Acosta”. Revista Médica. Cuarta etapa, No. 1, pág. 71, 1967.

Junta General de la Beneficencia de Cundinamarca, Bogotá. Acuerdo No. 6 de 1948 (3 de febrero), Acuerdo No. 41 de 1950, Resolución No. 13 de 1953 (noviembre 3).

MOJICA, C.J. "El tratamiento de la endometritis puerperal con los antivirus de estreptococo". Rev. Méd. de Colombia. Vol. I. No. 10, 1931.

MONCADA, L.E. "Septicencia puerperal y su tratamiento". Tesis de grado, Universidad Nacional. Imprenta José M. Rosales \& Cía., Bogotá, 1919. 